\title{
Correction to: Philosophy in the age of science
}

\section{J. Beale and I. J. Kidd, Eds.: Wittgenstein and scientism. Routledge, 2017, 232pp, \$140 HB}

\section{Mariam Thalos ${ }^{1}$}

Published online: 6 December 2018

(c) Springer Nature B.V. 2018

\section{Correction to: Metascience}

https://doi.org/10.1007/s11016-018-0359-2

In "Philosophy in the age of science," a review of J. Beale's and I. J. Kidd's edited volume, Wittgenstein and scientism, by Mariam Thalos, Chon Tejedor was mistakenly referred to as he, rather than she.

We apologize for this error.

The original article can be found online at https://doi.org/10.1007/s11016-018-0359-2.

Mariam Thalos

m.thalos@gmail.com

1 Department of Philosophy, University of Tennessee, Knoxville, USA 